\title{
0 ensino do/para o jornalismo e a formação profissional
}

Fernando Cascais*

O quadro actual do ensino do jornalismo em Portugal justificaria o adágio popular de que "não há fome que não dê em fartura". De facto, depois de uma tentativa fracassada de institucionalização de um curso superior de Jornalismo em $1971^{1}$, os primeiros cursos universitários, mas de Comunicação Social, surgiram em 1979 (Universidade Nova de Lisboa) e 1980 (Instituto Superior de Ciências Sociais e Políticas/ Universidade Técnica de Lisboa). Só em 1974 ou, como se verá adiante, em 1984 entraram nas redacções portuguesas os primeiros diplomados em Comunicação Social, o que fez de Portugal um caso ímpar de atraso na formação superior direccionada para o exercício do Jornalismo.

Para trás ficara uma era de censura e de subalternização do jornalismo e dos jornalistas que fez do ensino do jornalismo uma questão política, logo uma proibição. Reconquistada a liberdade de expressão em 25 de Abril de 1974, a formação para o jornalismo, a nível universitário, tardou ainda cinco anos.

Mas 24 anos depois do primeiro ano lectivo com ensino da Comunicação Social o País também é um caso singular de abundância. A oferta a nível nacional do sector público em formação académica superior para o ano lectivo 2003-2004 em áreas como Jornalismo, Comunicação Social, Ciências da Comunicação ou conjugações destes domínios ${ }^{2}$, totaliza 14 cursos - seis universitários e oito politécnicos - e 667 vagas (347 no ensino universitário e 320 no politécnico) para o primeiro ano dos cursos. Somando o ensino privado, atingem-se 23 cursos (mais quatro universitários e cinco politécnicos), e o número anual de vagas disponíveis eleva-se para cerca de um milhar.

\footnotetext{
* Director do Centro Protocolar de Formação Profissional para Jornalistas (CENJOR), docente universitário. Ex-presidente da Associação Europeia de Formação em Jornalismo (1999/2000).

${ }^{1}$ Através da Escola Superior de Meios de Comunicação Social, escola de ensino superior privada ligada a um dos principais grupos económicos portugueses, o Grupo Quina (à data proprietário do Diário Popular, do Jornal do Comércio e do Record). Os primeiros diplomados em Jornalismo saíram da Escola em 1974, após o 24 de Abril, e o estabelecimento entrou em colapso, na sequência da nacionalização da banca, em 1975, e, após longa agonia, extinguiu-se no início da década de 80 (Cascais, 2003).

${ }^{2}$ Excluem-se cursos de áreas afins, como Fotografia, Cinema, Audiovisual, Tecnologias da Comunicação, Artes Gráficas, Multimédia, Comunicação Empresarial, etc.
} 
Apesar deste "milagre da multiplicação dos cursos”, como lhe chamou Mário Mesquita, a verdade é que a problemática envolvida na formação em jornalismo quase não tem sido objecto de investigação em Portugal ${ }^{3}$.

A multiplicação da oferta, a diversidade de conteúdos, a imprecisão de alguns objectivos de formação são apenas algumas das questões que emergem no mar de problemas onde desaguou a "crise de crescimento" deste campo de ensino.

Uma simples preposição gramatical levanta a primeira questão: ensino do jornalismo ou para o jornalismo? Do sugere uma preparação científica num campo já definido e estruturado de saberes e de técnicas, tendendo para uma certa "universalização" da formação académica, um modelo paralelo às outras profissões com as quais o Jornalismo por vezes gosta de se comparar - o Direito, a Medicina; para abre o campo de formação ao nível do acesso, diversificando a formação de base e tornando a componente jornalística um complemento, embora indispensável.

O primeiro obstáculo ao ensino do jornalismo é a volumosa e programaticamente descontrolada oferta formativa superior ${ }^{4}$. A diversidade é positiva, mas sem debate e posterior coordenação não se consolidará um corpo de conhecimentos reconhecidamente estruturantes de uma actividade profissional.

Outra questão, não menos imediata, é a do próprio profissionalismo. Para muitos o jornalismo não é uma profissão, ou é uma profissão de modelo diferente das suas comparações habituais (advocacia, medicina); ou trata-se de uma profissão deliberadamente "vaga”, nos termos propostos por Denis Ruellan (Ruellan, 1997).

Para Hugh Stephenson (Stephenson, 2003), hoje o jornalismo é menos claramente definido como profissão do que há 25 anos, o que se justifica com dois tipos de argumentos, um tecnológico e outro económico.

Stephenson, co-autor de um vasto estudo realizado em 1990 sobre a formação dos jornalistas na Europa ${ }^{5}$, actualizou em 2003 aspectos desse trabalho relativos à forma-

\footnotetext{
${ }^{3}$ Manuel Pinto sublinhou a necessidade de "fazer da formação em jornalismo (história, estrutura curricular, métodos, conteúdos) objecto de investigação" " "O ensino e a formação na área do jornalismo em Portugal - Notas sobre uma "crise de crescimento'”, comunicação apresentada no I Congresso Luso-Galego de Estudos Jornalísticos, Santiago de Compostela, 29-30 Outubro, 2002).

${ }^{4}$ Mário Mesquita propôs em 1987 a criação de um Conselho Superior do Ensino da Comunicação Social e do Jornalismo, como órgão consultivo da Direcção-Geral do Ensino Superior, constituído pelos presidentes dos conselhos científicos das escolas e departamentos de Comunicação Social e jornalismo existentes no país, pelos presidentes do Sindicato dos Jornalistas e das Associações da Imprensa Diária e Não-Diária e pelo Director-Geral do Ensino Superior. Entre as funções do Conselho estaria a procura de harmonização dos curricula (II Congresso da AIND - Aposta no Futuro, 1988, AIND, Lisboa, pp. 85-88). O Congresso realizou-se em Maio de 1987, no Funchal. Depois desta tentativa sem resultados, a Universidade da Beira Interior (UBI) recebeu na Covilhã, em Novembro de 1994, o I Encontro dos Cursos de Comunicação (ECCO) das Universidades representadas no Conselho de Reitores das Universidades Portuguesas. Participaram sete cursos, foi elaborada uma proposta de estatutos para o ECCO, mas o movimento não teve sequência. Em Setembro de 2003, o Grupo de Trabalho da Associação Portuguesa de Ciências da Comunicação (SOPCOM) realizou na Universidade do Minho (Braga) o I Encontro Nacional sobre o Ensino do Jornalismo em Portugal. Ao longo de duas décadas e meia, a reflexão e as possibilidades de coordenação ainda não passaram de iniciativas isoladas.

${ }^{5}$ Hugh Stephenson e Pierre Mory, 1991, La Formation du journalisme en Europe, Association Européenne de Formation en Journalisme, edição do CFPJ, Paris.
} 
ção contínua (Stephenson, 2003), e voltou a sublinhar as diferentes atitudes nacionais relativamente à formação dos jornalistas e à formação para o jornalismo.

Numa perspectiva internacional, nomeadamente europeia, a globalização empresarial e a convergência tecnológica dos media não geraram fenómenos semelhantes ao nível da formação. A história e a cultura jornalística nacional predominam, independentemente da permanente modificação técnica ao nível dos perfis profissionais no sector.

Antes dos primeiros cursos universitários de Comunicação Social pós-25 de Abril, a classe profissional ensaiou a formação profissional e, nos anos 80, abriram dois centros, um no Porto e outro em Lisboa. Enquanto no primeiro caso a iniciativa envolveu empresas e profissionais, no segundo a estes parceiros juntou-se o Estado (sobretudo via Instituto do Emprego e Formação Profissional).

Está por fazer a história crítica do período 74-79 e da década de 80, essenciais para a contextualização e compreensão do problema do ensino do jornalismo nas condições históricas, sociais e culturais portuguesas.

Não desenvolvendo este ponto, importa, no entanto, analisar o posicionamento do Centro Protocolar de Formação Profissional para Jornalistas (CENJOR) no contexto actual do ensino do/para o jornalismo.

\section{Actividade e posicionamento do CENJOR}

O CENJOR foi criado em $1986^{6}$ através de um acordo entre dois institutos públicos ${ }^{7}$, o Sindicato dos Jornalistas e as Associações Portuguesa de Imprensa ${ }^{8}$ e Associação da Imprensa Diária. Estado, profissão e empresas estão assim representados nos seus órgãos estatutários.

A actividade formativa foi iniciada em 1988. Em 15 anos (1988-2002) realizou 1122 cursos de formação, que tiveram 14133 participantes ao longo de 127250 horas. A média anual foi de 75 cursos, 8483 horas (quase 24 horas/dia), e 942 formandos. Nos últimos seis anos (1997-2002), a média anual subiu para 97 cursos, 12131 horas e 1454 formandos.

Os cursos variam entre 30 e 1500 horas, consoante os objectivos e conteúdos, e têm sido realizados por todo o País, contando em grande parte com o apoio de programas subsidiados pelo Fundo Social Europeu.

No plano internacional, o CENJOR mantém uma vertente de trabalho regular com os profissionais e as empresas dos PALOP e de Timor-Leste. Na Europa, mantém contactos e parcerias de trabalho com institutos de formação e universidades

\footnotetext{
${ }^{6}$ Portaria no 667/86, publicada no Diário da República de 7 de Novembro.

${ }^{7}$ Instituto do Emprego e Formação Profissional e Instituto da Comunicação Social. À data da assinatura do protocolo este último sector era representado pela Direcção-Geral da Comunicação Social, antecessora do actual Instituto.

${ }^{8}$ Designação actual da então Associação da Imprensa Não-Diária. A Associação Portuguesa de Imprensa conserva, no entanto, a sigla AIND.
} 
pertencentes à Associação Europeia de Formação em Jornalismo. Esta organização agrupa meia centena de estabelecimentos de ensino superior e de formação profissional e, entre 1997 e 2000, o CENJOR foi membro da sua direcção.

O Centro ministra formação nas áreas do jornalismo em imprensa, rádio, televisão, on-line, multimédia e fotografia, em especialidades como paginação, infografismo, técnicas vocais; e, em parceria com instituições dos respectivos sectores, desenvolve seminários direccionados para temas específicos (assuntos europeus, segurança e defesa, sistema judicial, etc.).

Com um corpo de formadores totalmente externo e quase exclusivamente formado por jornalistas profissionais e técnicos experientes nas respectivas áreas de formação, o programa para 2004 envolve 243 cursos, num total de 14259 horas de formação. Sinteticamente, o plano reparte-se por seis áreas - Imprensa, Rádio, Televisão, On-line e Multimédia, Fotojornalismo e Formação de Formadores -, três especialidades de formação (profissionalizante, aperfeiçoamento e especialização) e três tipos de público (estudantes ou diplomados candidatos à profissão; profissionais e colaboradores da Comunicação Social; e outros profissionais que se relacionam com os media). O campo de formação será alargado em 2004: produção audiovisual, repórter de imagem, edição e montagem audiovisual, webdesign e design multimédia.

Os cursos variam entre 15 horas, em seminários intensivos, e cerca de mil (na especialização em Jornalismo). Esta especialização - um curso anual predominantemente prático, com 12 a 14 participantes - visa preparar para o exercício profissional em todos os meios (imprensa, rádio, televisão, on-line) diplomados com cursos supe-riores preferencialmente em áreas importantes para o tratamento jornalístico da actualidade (economia, biologia, história, sociologia, direito, etc.). O curso integra- -se numa corrente, com alguma expressão a nível europeu, que forma em jornalismo simultaneamente com (ou sequencialmente a) outras formações académicas. Do ponto de vista do perfil profissional, este modelo favorece a especialização.

\section{Formação profissional e formação académica}

As características dominantes da formação profissional, na perspectiva do CENJOR, são:

- constante reformulação, adaptando os programas à evolução do sector, nas suas várias vertentes, como a profissional e a empresarial;

- complementaridade em relação à formação académica superior na área da Comunicação e do Jornalismo;

- conteúdo formativo predominantemente prático, baseado no saber-fazer e no saber-analisar criticamente o que se vai produzindo;

- prioridade à formação contínua, privilegiando o aperfeiçoamento, a actualização, a reciclagem e, muito em particular, a especialização;

\footnotetext{
${ }^{9} \mathrm{~A}$ tarimba foi a "escola" do jornalismo português até meados da década de 80, e tanto a legislação (Estatuto do Jornalista) como a política sindical têm mantido o acesso profissional aberto, ou seja, também pela via da tarimba.
} 
- equilíbrio formativo entre técnicas jornalísticas e temas de relevância jornalística;

- favorecer conhecimentos e fornecer competências técnicas e tecnológicas de modo tão intensivo quanto possível.

Esta caracterização aponta algumas questões essenciais:

1. A formação profissional, em vez de uma via autónoma de acesso ao jornalismo, deve ser o complemento de outra formação, seja universitária ou tarimbeira ${ }^{9}$. No primeiro caso, é o complemento prático; no segundo o complemento teórico-prático ${ }^{10}$.

2. A formação profissional é a via mais flexível e imediata de actualização de técnicas e de conhecimentos e, sobretudo, é uma via para a especialização que a formação académica na área da Comunicação geralmente não contempla.

3. A formação profissional prioriza as competências práticas, pelo que a sua actividade tende para o que as empresas esperam dos candidatos; inversamente, porém, os candidatos esperam da formação profissional as competências que levarão as empresas a admiti-los.

4. A formação académica aproxima os futuros jornalistas do público, dos cidadãos, destinatários essenciais da sua actividade profissional; a formação profissional aproxima-os do mundo profissional e empresarial. Porém, a formação exclusivamente interna ou ligada a uma determinada empresa é uma via para a deformação profissional. As opções editoriais da empresa tendem a substituir os programas de formação independentes.

Desta relação complexa formação académica-formação profissional-empresas emerge agora outro problema difícil: a contradição das exigências. Ao mesmo tempo que aumenta a exigência ao nível da formação do candidato a jornalista, diminui a exigência do trabalho que se pede nas redacções a esse candidato ${ }^{11}$.

\section{Ir à formação profissional porquê?}

A relação do ensino com os candidatos ao jornalismo parece indiciar desajustamentos sobre os quais importa reflectir. Três inquéritos e estudos recentes (de 2002), apesar das suas limitações, apontam esses indícios.

Entre Março e Abril de 2002 o CENJOR realizou um inquérito aos seus formandos ${ }^{12}$.

\footnotetext{
${ }^{10}$ Como consagra a Portaria que instituiu o curso de estágio no âmbito do Estatuto do Jornalista.

${ }^{11}$ Num dos recentes livros-escândalo da edição francesa dedicada aos media (Ruffin, 2003: 101) a questão é assim colocada: "não é fácil para o Centro (de Formação de Jornalistas de Paris) gerir as contradições do sistema: de um lado, os grandes media aproveitam-se da concorrência entre os candidatos ao jornalismo e exigem cada vez mais diplomas, títulos escolares prestigiados. Do outro, são confiadas tarefas estéreis aos estagiários: redacção de telexes, pequenos inquéritos de rua, etc. A distância entre a formação inicial e o destino habitual dos intelectuais dá que pensar. Tudo isso para isto? Montaigne, Pascal, Kant, Einstein para quê? (...) Para redigir a rubrica 'consumo' de uma revista feminina?" ${ }^{12}$ Este inquérito integrou-se numa pesquisa de Rita Veloso Mendes para o trabalho "Profissão jornalista: Motivações e expectativas face ao futuro dos formandos do CENJOR”, tese de licenciatura em Sociologia, ISCTE, 2002. Dos 259 formandos inquiridos entre 13 de Março e 27 de Abril obtiveram-se 139 respostas válidas (cerca de 54\%).
} 
Dos 139 inquiridos:

- $68 \%$ possuíam ou frequentavam licenciaturas na área da Comunicação e 20\% na área das Ciências Sociais;

- $44 \%$ já exerciam actividade profissional na Comunicação Social;

- $41 \%$ eram estudantes.

Como principal motivo para frequentarem o CENJOR indicaram o "aumento de conhecimentos" (41\%). Segunda razão mais apontada (25\%): "por ser a instituição mais indicada para a área". Outros (15\%) apontaram acordos entre o estabelecimento de ensino que frequentam e o CENJOR e a credibilidade do CENJOR (14\%). Finalmente, 5\% referiram "sugestão patronal".

Entre os estudantes da área da Comunicação, a formação prática no CENJOR é classificada como "muito importante" (59\%) ou "indispensável" (20\%).

A formação profissional é vista pelos candidatos ao jornalismo, mesmo para os que cursam a universidade, como uma mais-valia importante. Um quarto dos inquiridos considerou uma instituição de formação prática como "a mais indicada" para a sua preparação.

Colocados perante a importância relativa da formação académica e da formação profissional, favorecem claramente a segunda:

- a formação académica é “importante” para 52,5\%, enquanto 47,5 \% a consideram "muito importante";

- a formação profissional é "muito importante" para 85,6 \%, enquanto $14 \%$ a classificam de "importante".

Quanto à formação necessária para o jornalismo profissional, a maioria das opiniões divide-se entre quatro itinerários formativos, sendo o mais indicado $(29,5 \%)$ a simultaneidade de formação académica superior e de formação profissional, ambas na Comunicação Social. Com $20 \%$ de escolhas surgem duas opções: só formação profissional em jornalismo e formação profissional em jornalismo com formação académica superior em qualquer outra área. Finalmente, 16\% das opiniões defendem apenas formação académica superior na área da Comunicação Social.

Um inquérito sobre necessidades de formação lançado em 2002 pelo Sindicato dos Jornalistas e pelo CENJOR proporciona outros dados interessantes ${ }^{13}$, a partir da análise de 147 respostas de indivíduos exercendo actividade jornalística ${ }^{14}$ e quase igualmente repartidos entre sexos (49\% homens; $51 \%$ mulheres). O inquérito foi lançado através da Internet, a partir do site do Sindicato, mas registe-se que $72 \%$ das respostas foram enviadas de Lisboa.

Pode admitir-se que a resposta a um inquérito sobre necessidades de formação indicia de algum modo a existência de tal necessidade, bem como disponibilidade

\footnotetext{
${ }^{13}$ A análise dos inquéritos foi feita por Ana Cristina Vieira, técnica superior do CENJOR.

${ }^{14}$ Apenas dois dos inquiridos referem a situação de desemprego. O maior número de respondentes declarou trabalhar na imprensa (43\%), seguindo-se a informação on-line, rádio, televisão e agência.
} 
para aquisição de novos conhecimentos ou competências, ou para aperfeiçoamento de conhecimentos ou competências existentes.

Neste contexto é significativo que entre os respondentes:

- $64 \%$ tenham entre 21 e 30 anos;

- $61 \%$ possuam licenciatura ou bacharelato (predominantemente na área da Comunicação);

- $60 \%$ tenham menos de cinco anos de actividade profissional (44\% possuem entre dois e cinco anos e $16 \%$ menos de um ano);

- $90 \%$ respondam afirmativamente à necessidade de especialização.

Num ponto do questionário pediu-se a definição do papel da formação na respectiva carreira profissional. Entre quatro hipóteses possíveis, a mais indicada foi a sua importância para um "melhor desempenho", seguida da "satisfação pessoal”. Só depois surge a "progressão na carreira" e finalmente a "garantia de emprego". Conclusão: a falta de preparação, de segurança ou mesmo de conhecimentos para a actividade profissional é mais relevante do que itens relacionados com o emprego e a carreira.

\section{A formação é precisa? Qual? Como?}

Durante os dois últimos meses de 2002 o site do Sindicato dos Jornalistas ${ }^{15}$ manteve em linha um inquérito com a seguinte pergunta: "Considera absolutamente necessário ter-se formação académica superior na área da Comunicação Social para se ser jornalista?"

O inquérito, de pergunta fechada (sim ou não), recebeu 386 respostas. O "não" foi claro vencedor, com dois terços das preferências (66\%), cabendo ao "sim”, 34\%.

Além da cruzinha, 35 votantes (alguns identificaram-se como estudantes e jornalistas) também comentaram a questão. O teor dos comentários reflecte sensivelmente o resultado quantitativo final. De facto, excluindo quatro comentários oriundos do Brasil, por terem como referência um contexto diferente, os 31 restantes distribuem-se entre $68 \%$ de "nãos" e $32 \%$ de "sins".

Após quase um quarto de século de formação académica superior na área da Comunicação, com uma oferta anual da ordem das mil novas vagas, há um discurso significativo sobre profissionalização em Jornalismo que continua a resistir à licenciatura na área da Comunicação Social.

Porquê? A resposta é complexa. Envolve elementos históricos, políticos e culturais, a questionável cultura profissional do jornalismo português, o seu sinuoso processo de profissionalização, ou o processo de desprofissionalização eventualmente em curso.

Da análise do "porque não" e do "porque sim” ao inquérito sindical podem ficar algumas pistas para reflexão.

\footnotetext{
${ }^{15}$ Este foi o primeiro inquérito lançado pelo site do SJ (www.jornalistas.online.pt) depois da sua reformulação.
} 
Identificam-se seis razões distintas para o "não"16. O maior volume (precisamente um terço, 33\%) das respostas negativas baseia-se na ideia de que o fundamental é a prática, alcançada por diferentes vias - um curso de formação profissional, um estágio, a simples "escola da vida". A maioria das recusas tende para:

- a valorização da "tarimba" face à formação académica;

- uma certa ideia de "facilitismo" profissional;

- uma concepção predominantemente tecnicista do exercício profissional.

O segundo argumento "não" (29\%) defende a formação académica superior, mas em qualquer área. O que prefigura um campo profissional de fronteiras imprecisas, sem um corpo de conhecimentos reconhecido e estruturante, porque baseado em formações díspares apenas unificadas pelo objectivo final de exercício de uma mesma actividade.

Em terceiro lugar (19\%), surge um efeito de identificação, precisamente com nomes e rostos de jornalistas conhecidos (e apreciados) mas que não têm cursos superiores no currículo. A justificação de que existem bons jornalistas sem cursos superiores é um argumento que o tempo tenderá a esbater, dado o constante aumento percentual da formação superior na classe profissional, mas dificilmente desaparecerá, dado o carácter aberto desde sempre defendido por órgãos tutelares, como o Sindicato dos Jornalistas, para acesso à actividade profissional.

A quarta razão (14\%) reparte-se por dois argumentos. O primeiro poderia julgar-se extinto, mas não está. Trata-se da ideia de que "se nasce" jornalista, o que representa a oposição total à necessidade ou utilidade da formação académica superior. O segundo argumento surpreende pela expressão muito inferior à que seria de esperar, atendendo a um dos discursos mais frequentes sobre os cursos superiores da área da Comunicação Social: são muito teóricos, ou pouco práticos, ou insuficientemente profissionalizantes.

Finalmente, a razão menos presente $(10 \%)$ é a de carácter mais pragmático ou economicista: não há mercado de trabalho que justifique a formação académica superior, ou, mais frontalmente ainda, a perspectiva de emprego não passa de uma sucessão de estágios.

Reduzido a menos de um terço das respostas, o "sim” à absoluta necessidade de formação académica superior na área da Comunicação Social, distribui-se por três argumentos mais representativos.

O mais forte (presente em $70 \%$ das respostas) é o que vê essa formação como defesa e protecção dos diplomados. Estabelece, por vezes, a analogia com profissões consagradas como tal - médicos e advogados. Esta é uma perspectiva de exclusividade no acesso, visando claramente impedi-lo a possuidores de habilitações académicas (mesmo superiores) diferentes. Este fechamento do campo profissional é uma resposta à “invasão” por outros, com ou sem diplomas.

\footnotetext{
${ }^{16}$ Note-se que as percentagens relativas ultrapassam os cem por cento porque algumas respostas contêm ou combinam mais do que um argumento entre os identificados.
} 
Num plano mais secundário (29\%), o “sim” é defendido como uma garantia de ética e rigor profissional contra uma espécie de jornalismo "trash" e contaminado por "pseudojornalistas".

Finalmente, a terceira razão (20\%) é uma espécie de "nim": a necessidade absoluta é defendida sob condição - a de ter maior componente de formação prática.

Há muitas questões em torno da problemática do ensino do jornalismo em Portugal, tal como há necessidade de debate e de estudos sobre conteúdos e programas, níveis e objectivos de formação. A relação do campo do Jornalismo com a globalizante Comunicação não será um dos menores problemas. Mesmo que não haja fracturas (entre Jornalismo e Comunicação, entre universidade e profissão, entre formação teórica e prática, entre ensino e tarimba) sentem-se fissuras.

\section{Referências bibliográficas}

Cascais, F. (2003). Ensino do Jornalismo - Contributo para a sua história/período 1968-1974), trabalho para defesa do Diploma de Estudos Avançados, Setembro de 2003 (Programa de Doutoramento em Comunicação Social, Universidade Complutense, Madrid)

Mesquita, M. (1994). 'A Educação para o jornalismo: Uma perspectiva sobre Portugal', comunicação apresentada ao II Congresso dos Jornalistas de Língua Portuguesa, Rio de Janeiro, Dezembro de 1994.

Pinto, M. (2002). 'O Ensino e a formação na área do jornalismo em Portugal - Notas sobre uma 'crise de crescimento’, comunicação apresentada ao I Congresso Luso-Galego de Estudos Jornalísticos, Santiago de Compostela, Outubro de 2002.

Ruellan, D. (1997). Les "Pro" du journalisme - De l'État au statut, la construction d'un espace professionnel, Grenoble: Presses Universitaires.

Ruffin, F. (2003). Les Petits soldats du journalisme, Paris: Éditions les Arèes.

Stephensen, H. (2003). Taking Journalism Further - Mid-Career Training in a European context, Maastricht: EJC. 